Portland State University

PDXScholar

1991

\title{
Output of compression hearing aids with transient and continuous input stimuli
}

Carol Ann Gregory

Portland State University

Follow this and additional works at: https://pdxscholar.library.pdx.edu/open_access_etds

Part of the Speech and Hearing Science Commons

Let us know how access to this document benefits you.

\section{Recommended Citation}

Gregory, Carol Ann, "Output of compression hearing aids with transient and continuous input stimuli" (1991). Dissertations and Theses. Paper 4174.

https://doi.org/10.15760/etd.6058

This Thesis is brought to you for free and open access. It has been accepted for inclusion in Dissertations and Theses by an authorized administrator of PDXScholar. Please contact us if we can make this document more accessible: pdxscholar@pdx.edu. 
AN ABSTRACT OF THE THESIS OF Carol Ann Gregory for the Master of Science in Speech Communication: Speech and Hearing Sciences presented November 6. 1991.

Title: Output of Compression Hearing Aids With Transient and Continuous Input Stimuli

APPROVED BY THE MEMBERS OF THE THESIS COMMITTEE:

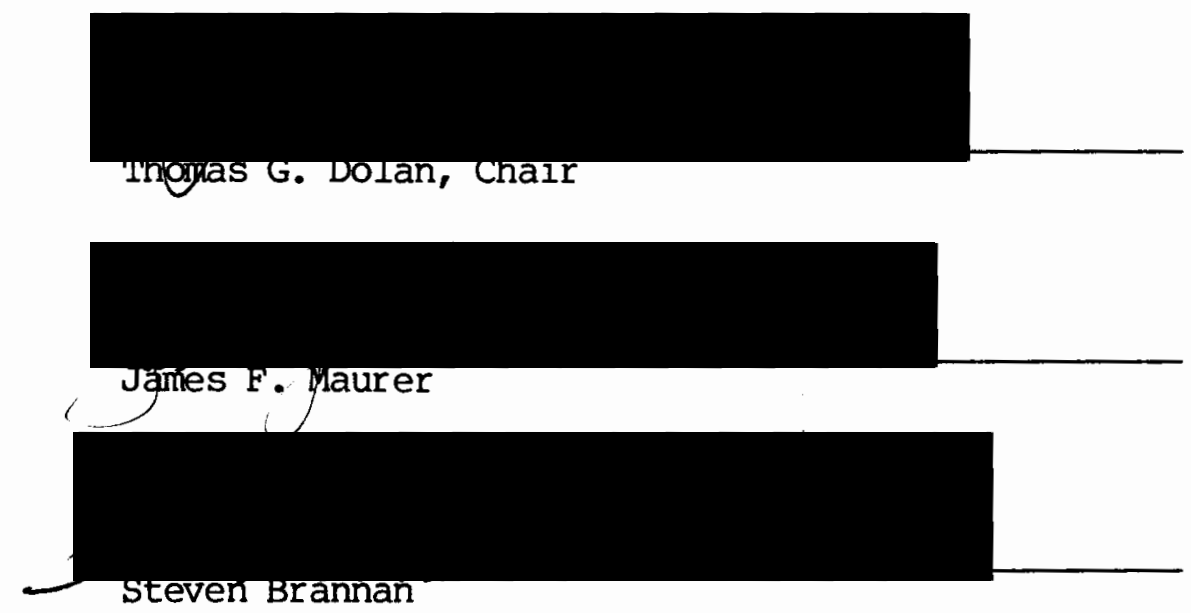

The purpose of this study was to determine whether the compression circuit of a hearing aid could be activated by a high frequency biasing tone such that its output for a transient stimulus could be made to approximate that of a continuous tone alone. Sufficient compression activation by a transient stimulus would mean that this type of hearing aid could be used in obtaining aided ABR measurements, since transient stimuli are commonly used for this procedure. Four hearing aids were used, and transient or continuous stimuli were introduced either alone 
or in combination with an 8 or $10 \mathrm{kHz}$ biasing tone. The biasing tone was either held at one constant level or varied in intensity along with the transient or continuous signal.

The results indicate that for presentation of a transient signal alone, output reduction occurred for only two of the hearing aids, but not to the same degree as for the continuous $3 \mathrm{kHz}$ tone presented alone. When a biasing tone was added and varied in intensity with the stimulus, successful compression activation was noted for two of the aids, while the remaining two aids showed output levels that were either higher or lower than the target values. When the biasing tone was presented at a constant level, however, too much output reduction occurred and a linearization of the input/output function was noted for all the aids, whether the primary signal was transient or steady state.

Although the results of this study indicate that compression activation can be made to occur for presentation of a transient stimulus, it was noted that each hearing aid exhibits different frequency response characteristics, compression thresholds, and attack and release times, and so the success of this procedure will depend upon which hearing aid is used. This would necessitate testing each hearing aid in the manner described prior to its use in ABR testing, to determine if the procedure is successful for that particular aid. If not evaluated beforehand, hearing aid output may be higher or lower than believed, leading to inaccurate ABR interpretation. Unfortunately, such prior testing would be time consuming and would require a great deal of additional instrumentation. As such it may not be practical for clinical use. It was suggested that further study in this area should 
concentrate on the investigation of the output linearization phenomenon, using broad band stimuli that more closely approximate sounds encountered in everyday situations. It is hoped that results of future research will further define the output characteristics of compression hearing aids, and lead to greater user satisfaction. 
OUTPUT OF COMPRESSION HEARING AIDS WITH

TRANSIENT AND CONTINUOUS INPUT STIMULI

by

CAROL ANN GREGORY

A thesis submitted in partial fulfillment of the requirements for the degree of

MASTER OF SCIENCE

in

SPEECH COMMUNICATION:

SPEECH AND HEARING SCIENCES

Portland State University

1991 
TO THE OFFICE OF GRADUATE STUDIES:

The members of the Camittee approve the thesis of Carol A. Gregory presented November 6, 1991.

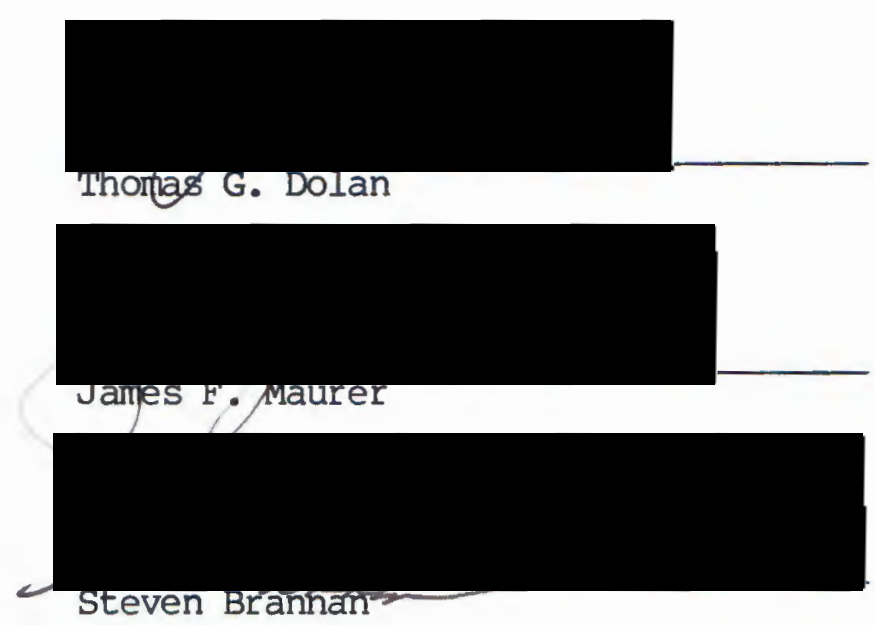

APPROVED:

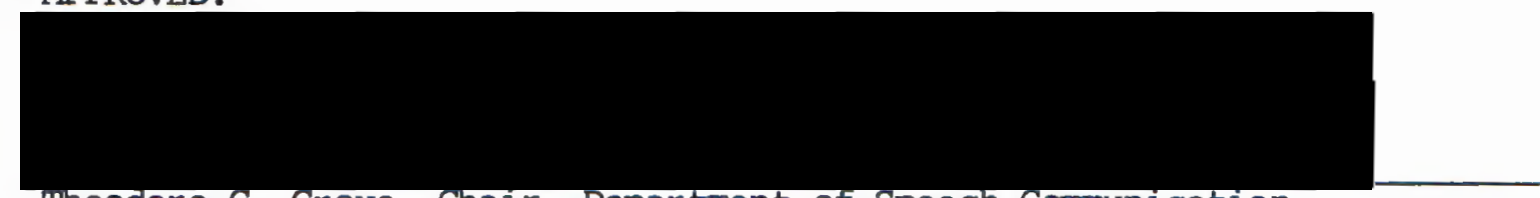

Theodore G. Grove, Chair, Department of Speech comunication

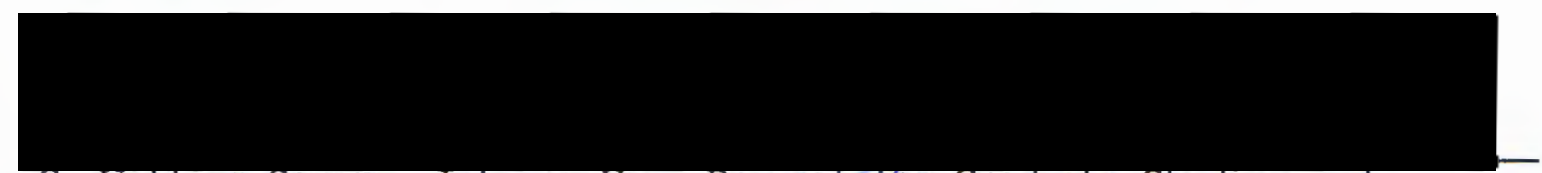

c. william savery, Inter im vice provosf for Graduate studies and Research 


\section{ACKNOWLEDGEMENTS}

I wish to thank Dr. Thomas Dolan for his assistance and guidance during the course of this study. I also wish to express my appreciation to the members of my family, particularly to my husband David, for their years of patience and support during the course of my graduate studies. 
TABLE OF CONTENTS

PAGE

ACKNOWLEDGEMENTS ........................ . iii LIST OF TABLES . . . . . . . . . . . . . . . . . . v v LIST OF FIGURES . . . . . . . . . . . . . . . . . . . vi CHAPTER

I INTRODUCTION ....................... 1

II REVIEW OF THE LITERATURE . . . . . . . . . . . . 6

Hearing Aids and ABR ............ 6

III METHODS . . . . . . . . . . . . . . . 13

Test Conditions ............. 13

Acoustic Signals . . . . . . . . . . . 14

Instrumentation ............... 15

Procedures ................. 16

IV RESULTS ...................... 18

V DISCUSSION . . . . . . . . . . . . . . . 29

REFERENCES . . . . . . . . . . . . . . . . . 32 APPENDIX . . . . . . . . . . . . . . . . . . . 34 


\section{LIST OF TABLES}

TABLE

PAGE

I List of Hearing Aids and Attack/Release Times . . . . . I3 


\section{LIST OF FIGURES}

\section{FIGURE}

1. Input/output functions for all four hearing aids using a continuous $3 \mathrm{kHz}$ tone as input, illustrating the effects of maximum (squares) vs. minimum campression setting (circles)............. 19

2. Input/output functions for all four hearing aids, illustrating the effects of maximum $(\Delta)$ vs. minimum (t) compression setting on the aid's transduction of a $3 \mathrm{kHz}$ transient signal . . . 21

3. Output spectra for the starkey SMIIPPE hearing aid with maximum compression setting, illustrating the output levels for the frequency components present as the aid transduces a $3 \mathrm{kHz}$ transient signal presented alone at $90 \mathrm{~dB}$ P.E.L. (a), as well as the aid's transduction of the same imput signal presented in combination with a $105.2 \mathrm{~dB}$ SPL $10 \mathrm{kHz}$ biasing tone (b)

4. Input/output functions for all four hearing aids using a transient $3 \mathrm{kHz}$ imput signal presented in combination with a biasing tone that is presented at a constant level $(\mathrm{x})$ or varied in intensity $(\diamond)$ 
5. Input/output functions for all four hearing aids, using a continuous $3 \mathrm{kHz}$ tone as input presented in combination with a constant level $(\Delta)$ or variable level (x) biasing tone, with aid compression set to maximum . . . . . . . 27 


\section{CHAPTER I}

\section{INTRODUCTION}

Obtaining audiometric data on difficult-to-test patients is a challenging task for the audiologist. Certain patient populations, such as young children or individuals with severe mental or physical disabilities, are unable to provide reliable behavioral responses to audiometric stimuli. In these instances, the audiologist must make use of whatever objective measures are available, such as impedance testing, measurement of acoustic reflex thresholds, or the auditory brainstem response.

The auditory brainstem response (ABR) is of ten used to diagnose disorders of the auditory pathways, and can also provide reasonable estimates of threshold where behavioral data is unreliable or unavailable (Glattke, 1983; Schwartz \& Berry, 1985). This information has been used to prescribe hearing aids for non-responsive patients, where lack of definitive behavioral test results makes the decision to prescribe amplification a tentative one at best, especially in situations involving infants. ABR can also be used to evaluate the performance of aids on these patients, by providing an objective means of estimating aided thresholds (Mahoney, 1985) as well as providing data on the hearing aid's effect on the normalization of wave latencies (Hecox, 1983).

Beauchaine and Gorga (1988) described using a combination of ABR and 
real-ear measurements to define desired hearing aid output - haracteristics, while Mjoen (1981) based hearing aid prescriptions on the thresholds provided by ABR testing. Other researchers (Kileny, 1982; Hecox, 1983) described obtaining ABR responses from aided ears. Using aided $A B R$ responses to determine hearing aid output is basically done by presenting the stimulus to the hearing aid. The hearing aid then amplifies the stimulus and delivers it to the client's ear. Brainstem responses to the amplified signal are then recorded in the usual manner. It can then be determined what effect the aid has had on the amplitude, threshold, or latency of the ABR waveforms (Mahoney, 1985).

Stimuli used in ABR testing must be of short duration with rapid onset. Transient stimuli produce synchronous firing of neurons, and this synchrony of firing is essential to produce clear, identifiable waveforms that are used in the interpretation of ABR results. Types of stimuli typically used are clicks or tone bursts (Beauchaine \& Gorga, 1988).

Several issues have been noted in the use of aided ABR testing, such as alterations in the temporal and spectral characteristics of the stimulus as it is transduced by the hearing aid (Kileny, 1982; Beauchaine \& Gorga, 1988). Another important consideration is the manner in which signals are processed by hearing aids equipped with an automatic gain control (AGC).

The automatic gain control provides a form of output limitation that provides greater gain at low intensity imput levels, while reducing the aid's gain when input levels exceed a certain value (called the 
compression threshold). As such, the aid's output is not a linear function of its input. The output of the aid is reduced a short time after the presentation of the stimulus. This time lag between stimulus and AGC activation is referred to as the "attack time". Conversely, the time required for the aid to return to its prestimulus condition is referred to as "release time".

In fitting hearing aids, one must be aware of the phenomenon of loudness recruitment. A client exhibiting recruitment will experience an abnormal growth of loudness, characterized by a depressed level of discomfort. In prescribing hearing aids for these clients, it is important to select one that will provide satisfactory amplification, yet not exceed the discomfort level. This is of ten accomplished through providing the client with a hearing aid that is equipped with an automatic gain control. However, if one is trying to fit a hearing aid equipped with an $A G C$ circuit using $A B R$, it is of crucial importance to know how the aid is processing the transient stimuli, so that adequate ssumptions can be made regarding the level of the stimulus that is being delivered to the client's ear.

It has been questioned whether or not the brief stimulus used in $A B R$ testing actually succeeds in activating the AGC circuit, or if the stimulus is actually shorter than the aid's attack time (Mahoney, 1985; Kiessling, 1982; Berg, 1989). In addition, a possible interaction between attack and release time and the interstimulus interval (ISI) has been suggested (Gorga, Beauchaine, \& Reiland, 1987). In obtaining measurements from AGC equipped aids using short duration stimuli, the aid may not remain in campression due to the release time being shorter 
that the ISI. To circumvent these problems, it has been hypothesized that it may be possible to activate hearing aid compression through the simultaneous presentation of a continuous tone, called a "biasing tone" (Berg, 1989). The frequency of the continuous tone was above the high frequency cutoff of the aid, yet was still within the frequency response range of the aid's microphone. This avoided the possible problem of the continuous signal being amplified by the aid and appearing in its output. Theoretically, this procedure would allow the output of the aid to be compressed to the appropriate level, even with the presentation of a brief stimulus. Consequently, ABR testing should then yield results that are more indicative of the aid's true effect on the client's hearing.

Berg examined output as a function of input for several hearing aids using a transient signal (one cycle of a $3 \mathrm{kHz}$ tone). He found that with a biasing tone present, the aid's function could not be made to approximate that of a steady state signal in 4 out of the 5 aids studied. That is, the output of the aids was not reduced to the desired levels. Berg concluded that the success of this procedure may be dependent upon the aid used.

Berg's results also showed that when the compression was activated with a biasing tone having a constant level, the input/output function for the transient signal became linear. That is, in the presence of the extra signal the hearing aids appeared to function as linear instruments, with gain remaining constant as a function of input level. The question arises as to whether this phenamenon occurs for transient stimuli only, or if presentation of a biasing tone has a similar effect 
on the aid's output of a continuous signal. If it does, this defeats one of the main purposes of compression, which is to have higher gain for low imput levels than for high input levels.

In the present study, input/output functions were obtained for a continuous tone in combination with a biasing tone in order to determine if linearization also occurs when the primary signal is steady state. The study also extended that of Berg by obtaining input/output function for different hearing aids. This was done to determine if there are other instruments for which a biasing tone reduces the output for a transient signal to the level of a continuous tone presented alone. Finally, spectral analysis of the output of each aid was completed for a transient signal input, with and without the presence of a biasing tone. These procedures allowed us to determine whether there is a difference in how the compression circuit of hearing aids processes transient as opposed to continuous stimuli, and whether aided ABR testing using these kinds of aids is feasible. 
CHAPTER II

REVIEW OF THE LITERATURE

HEARING AIDS AND ABR

Use of the $\mathrm{ABR}$ for Hearing Aid Evaluations

Several investigators have studied the feasibility of prescribing and fitting hearing aids on the basis of aided ABR responses. Kileny (1982) reported using aided $A B R$ responses to determine which ear to fit, as well as to obtain information on hearing aid function, and found the procedure to be successful. Kileny noted advantages in using early brainstem responses in that they agree closely with behavioral thresholds, and are not susceptible to the effects of drugs, which are frequently used to induce sleep in pediatric clients.

Cox and Metz (1980) attempted to correlate hearing aid performance, $A B R$, speech recognition, and the configuration of the hearing loss. Their results indicated an agreement between minimum latency for wave $\mathrm{V}$ and speech recognition, while speech recognition could not be correlated with wave $\mathrm{V}$ thresholds. The authors suggested that using wave $\mathrm{V}$ latency might be a good indicator of hearing aid performance.

Wave $\mathrm{V}$ amplitude as a function of stimulus intensity has been investigated as a possible means of using the ABR in hearing aid selection. Normal versus pathological intensity/amplitude functions were used to fit hearing aids on children by Kiessling (1982) . 
Kiessling used a mathematical model imposed on the intensity-amplitude functions to predict desired hearing aid characteristics, such as the gain, type of compression, compression factor, and onset time.

McPherson and Clark (1983) simulated conductive hearing losses on normal hearing subjects, and then used ABR measurements to determine desired hearing aid settings. They concluded that wave $\mathrm{V}$ latencies would successfully be used to determine threshold, comfortable listening level, and level of discamfort. They also suggested a minimum value for wave $\mathrm{V}$ latency that could be used in adjusting the aid's maximum output. In the evaluation of $A B R$ results, wave latencies are frequently examined to determine how they are affected by changes in stimulus intensity. Increases in intensity have the effect of decreasing response latency. A plot of wave latency as a function of stimulus intensity is called a latency/intensity function. Typically wave $\mathrm{V}$ latency is used in the compilation of latency-intensity functions, as it is the most easily discernible component and is the one used for threshold determination (Schwartz \& Berry, 1985).

Hecox (1983) used ABR in the selection of hearing aids, and looked orimarily at latency-intensity functions. He concluded that the greater the displacement of the latency-intensity function from normal, the larger the gain requirements of the aid. Hecox noted that the presence of electrophysiological recruitment in one subject was indicated by a steep latency-intensity function. Providing the subject with linear amplification did not alter the slope of the funtion to more normal values. However, when aids containing AGC circuits were used, the values were normalized and the subject reported increased satisfaction 
with the aid's performance. Adjusting aids so that the value of wave $\mathrm{V}$ latency was less than 6 msec for a $60 \mathrm{~dB} H L$ signal proved to provide no advantage. Also, he concluded that amplification is unlikely to improve communicative function in patients with central auditory dysfunction.

Sanders (1983) found that the slow brainstem response (SN 10) to be a good means of determining aided and unaided thresholds, and found differences of less than $5 \mathrm{~dB}$ between this method and behavioral test results.

Problems with aided $\underline{A B R}$ testing

In spite of the apparent success of using aided ABR measurements to fit aids, several problems have been noted. ABR testing has been noted to be limited in the type of frequency specific information it provides. fecorded responses to clicks are biased toward the basal region of the cochlea, and as such can provide information only regarding sensitivity to mid and higher frequencies, generally 1-2 kHz and above (Kileny, 1982; Hecox, 1983; Beauchaine and Gorga, 1988). This fundamental limitation of ABR testing makes it difficult to determine the amount of low frequency gain provided by an aid, and may increase the difficulty in making a decision between different aids that may very well differ in low frequency output (Beauchaine \& Gorga, 1988). Information on low frequency sensitivity is also desirable for predicting successful hearing aid use in realistic communicative situations (Beauchaine, Gorga, Reiland, \& Larson, 1986).

Kileny (1982) noted that changes occur in the frequency spectrum of the stimulus as it is transduced by the hearing aid and also by the 
earphone used to deliver the signal. The resonant frequency of the earphone used seems to have an effect on this alteration in spectrum, with different phones producing characteristically different output. These changes in the stimulus will cause different excitation patterns of the basilar membrane, which in turn could affect ABR results. (Weber, Seitz, \& McCutcheon, 1981). Hall and Ruth (1985) reported that the high frequency energy of the stimulus is reduced in the aided condition, with uncertain effects on the $\mathrm{ABR}$.

Several authors note changes in the temporal characteristics of the stimulus in aided ABR testing. The transient stimulus has been described as producing "ringing" as it is transduced by the aid, causing a prolongation of the signal and deteriorating its rapid onset (Kileny, 1982; Kiessling, 1982; Mahoney, 1985). Transduction through earphones has also been noted to produce ringing and signal prolongation (Weber et al., 1981; Hall \& Ruth, 1985).

Temporal delays between input and output have been noted by several authors. Beauchaine and Gorga (1988) describe delays that vary with tone control settings, with delays of between .52 and $.55 \mathrm{msec}$ noted. If these delays are not accounted for in the evaluation of ABR results, it could result in a misinterpretation of wave latencies (Beauchaine et al., 1986). In addition, the method used for aided ABR testing necessitates placing the transducer some distance from the aid, which also adds to the delays imposed by the aid itself, and must also be taken into account (Hall \& Ruth, 1985).

Differences in stimulus intensity have also been described. Beauchaine and Gorga (1988) noted that intensity of the onset portion of 
the stimulus may be as much as $20 \mathrm{~dB}$ greater than the steady state portion, with this difference noted to decrease as the rate of presentation increased. For AGC equipped aids, the onset and steady state portions of the stimulus should be similar if the interstimulus interval is less than the aid's release time (i.e., as rate increases), and would indicate that the compression has been activated. However, increases in stimulus rate are known to elevate ABR threshold, which would invalidate this method of obtaining output compression during aided ABR measurements (Weber et al., 1981). It has been suggested that aided $A B R$ testing will not provide accurate information on hearing aid responses for long duration or steady state stimuli, and it is these types of stimuli that are used to describe output limitation characteristics (Beauchaine \& Gorga, 1988). Gorga et al. (1987) noted that steady state stimulus amplitudes agree with outputs obtained from hearing aid analyzers. They reported that onset amplitudes were higher than the steady state portion, indicating that the compression had been activated. However, since amplitude at stimulus onset differs from the steady state portion, aided ABR testing may not be valid since the responses obtained are linked to stimulus onset.

Other researchers have alluded to these problems in using compression aids. Kiessling (1982) noted the problem of short stimulus duration relative to the aid's attack time and stated that these time constraints make accurate ABR testing impossible. Mahoney (1985) also questioned the relationship between stimulus duration and attack time. Other research indicates that in normal frequency response testing, some frequencies will activate the compression circuit while others will not 
(Preves, Beck, Burnett, \& Teder, 1989). Preves et al. (1989) suggested that normal frequency response curves for AGC aids are not representative of how the aid functions in normal situations, such as in the processing of speech signals, where many frequencies may be present at once.

Berg (1989) attempted to determine whether the compression circuit of an AGC-equipped aid could be activated by the presentation of an extra or "biasing" tone. The biasing tone was presented simultaneously with a transient stimulus typical of the type used in ABR testing. The procedure was considered successful if the output of the aid in this condition could be made to approximate the aid's output for presentation of a continuous tone alone. Various combinations of signals were used. Berg noted that for presentation of the transient alone, aid output was not reduced for 4 out of the 5 aids studied. The aid for which output was reduced was noted to have the shortest attack time, and Berg concluded that successful activation of the compression circuit may be linked to individual aid characteristics. The biasing tones used were noted to activate the compression circuit, but output of the aid for simultaneous presentation of the transient was not reduced to the level of the continuous tone alone, indicating a difference in how the aid is processing the transient stimulus. For presentation of the biasing tone at a constant level, the transient output was noted to be reduced too much, and appeared to become linear in relation to imput.

The purpose of this study was to investigate whether the output of AGC hearing aids with transient signals as input could be made to approximate that of their output with a continuous tone presentation 
through the simultaneous presentation of a high frequency biasing tone. Input-output functions of several hearing aids were examined to determine if the activation of the AGC had taken place. Output spectra of the aids were also examined, to determine whether the continuous signal presented with the transient stimulus was present in the aid's output, which could affect the validity of ABR measurement. 


\section{CHAPIER III}

\section{METHODS}

Input/output functions were obtained from four hearing aids, two equipped with input compression, and two with output campression. These are listed in Table 1, along with their attack and release times. Transient or continuous stimuli were used as input, presented either alone or in combination with a high frequency biasing tone. Spectral analysis of the hearing aid output were performed in several conditions.

\section{TABLE I}

LIST OF HEARTNG AIDS AND ATTACK/RELEASE TIMES

\begin{tabular}{lcc}
\multicolumn{1}{c}{ Hearing Aid } & Compression Type & \multicolumn{2}{c}{ Measured } \\
\cline { 2 - 3 } & & $\frac{\text { Attack }}{\text { Release }}$ \\
Bosch Star 66F AGCl & Input & $5 / 23$ \\
Starkey SMII PPE & Input & $2 / 32$ \\
Widex G6H & Output & $4 / 250$ \\
Oticon E28P & Output & $3 / 42$
\end{tabular}

TEST CONDITIONS

Input/output functions were obtained for each of the following input conditions: 1 . continuous $3 \mathrm{kHz}$ tone with compression off or set to minimum; 2. continuous $3 \mathrm{kHz}$ tone with compression set to full on; 3. one cycle of a $3 \mathrm{kHz}$ tone with compression off or set to minimum; 4. one cycle of a $3 \mathrm{kHz}$ tone with campression set to full on; 5 . one 
cycle of a $3 \mathrm{kHz}$ tone presented with a continuous high frequency bias tone set at a constant $90 \mathrm{~dB}$ SPL; 6 . one cycle of a $3 \mathrm{kHz}$ tone presented with a continuous high frequency bias tone that is decreased in intensity in $5 \mathrm{~dB}$ steps from 90 to $50 \mathrm{~dB}$ SPL; 7. continuous $3 \mathrm{kHz}$ tone presented with a continuous high frequency bias tone set at a constant $90 \mathrm{~dB}$ SPL; 8. Continuous $3 \mathrm{kHz}$ tone presented with a continuous high frequency bias tone that is decreased in intensity in 5 dB steps from 90 to $50 \mathrm{~dB}$ SPL.

Output spectra were obtained for each of the aids under the following conditions: 1. presentation of the $90 \mathrm{~dB}$ P.E.L. transient alone; 2. presentation of the $90 \mathrm{~dB}$ P.E.L. transient with the biasing tone presented at the maximum level used in obtaining the input/output curves.

\section{ACOUSTIC SIGNALS}

The transient signal to be used was one cycle of a $3 \mathrm{kHz}$ tone having a rise time of $.83 \mathrm{msec}$ and a duration of $.33 \mathrm{msec}$, to be presented at a rate of 20 per second. The level of the transient was measured in peak equivalent level (P.E.L.), defined as being equivalent to the sound pressure level (SPL) of a continuous tone with the same peak-to-peak amplitude.

The activating (bias) signals to be used consisted of a 8 or $10 \mathrm{kHz}$ continuous pure tone, with the exact frequency determined by presenting the signal along with a continuous tone. The frequency of the biasing tone was then varied, and the one selected to use in the experiment was one which activated the compression circuit but did not show up in the 
output of the aid (i.e., was above the high frequency cutoff of the aid). This was determined by examination of the output spectra.

\section{INSTRUMENTATION}

Prior to conducting the experiment, the hearing aids were tested on a Fonix FP20 hearing aid test box that has been calibrated in accordance to ANSI S3.22-1982 standards. Using the test box, the volume control of the aids were set to the reference test position, as defined by ANSI for non-AGC aids.

Experimental measurements were conducted by means of a Buel \& Kjaer $(B \& K)$ hearing aid test box $(\# 4217)$. The hearing aids were attached to i HA-2 coupler placed in the test box. The sound in the coupler was transduced by means of a one inch condenser microphone ( $\& \& K$ type 4132) which was calibrated by a B \& $K$ type 2203 pistonphone and led to a B \& $K$ type 2203 sound level meter. The output of the sound level meter was then routed to a digital storage oscilloscope (Iwatsu SS-5802), which was used to measure the peak-to-peak output voltage of the hearing aid.

The one cycle transient was generated by a Modular Instruments signal generator system, which controlled the duration, repetition rate, phase and attenuation of the signal. The transient signal was then routed from the Modular Instruments system to the external imput of the $\mathrm{B} \& \mathrm{~K}$ hearing aid test box, and delivered via the test box loudspeaker. The attenuation of the transient signal after its initial setting on the Modular Instruments system was carried out by the $B \& K$ test box system. The $3 \mathrm{kHz}$ continuous tone was generated, routed and attenuated in the 
same manner.

The high frequency biasing tone was generated by a Circuitmate FG2 function generator, routed to a Leader LAT 45 attenuator, and transduced by a Realistic 40-1398 Piazoelectric loudspeaker tweeter, which was placed inside the $B \& K$ test box. The frequency of the biasing tone was determined by a Rockland 5840A FFT analyzer.

Output spectra for each of the aids under the previously indicated conditions was measured using a Rockland 5840A FFT analyzer, and printed using a Graphtek MP2000 x-y plotter.

\section{PROCEDURES}

Input/output functions were generated for each of the aids used under each of the previously stated conditions. During testing, the rolume control of the aids was set to the reference test position, which will be determined in accordance with procedures outlined by ANSI S3.22-1982 for non-AGC aids. Reference test position was determined with the aid's compression off or set to minimum. This position of the volume control was selected for use in the experiment because it is a more realistic approximation of the actual settings used by hearing aid wearers.

The high frequency biasing tone was set to a level determined by presenting the transient stimulus at $90 \mathrm{~dB}$ P.E.L. with the aid's campression full on. The level of the biasing tone was then adjusted so that the output of the transient was equal to that of a continuous $3 \mathrm{kHz}$ tone at $90 \mathrm{~dB}$ SPL with the compression full on. With the biasing tone at this level, it was presented simultaneously with the transient 
stimulus and kept at this constant level while the level of the transient was decreased in $5 \mathrm{~dB}$ steps from 90 to $50 \mathrm{~dB}$ P.E.L. The biasing tone was then presented again at this level along with the transient at $90 \mathrm{~dB}$ P.E.L, but was this time decreased in intensity in 5 $\mathrm{dB}$ steps along with the transient. The biasing tone was then set again at the starting level as previously defined, and presented with the 3 $\mathrm{kHz}$ continuous stimulus. The biasing tone was first kept at a constant level while the continuous tone was decreased in intensity fram 90 to 50 $\mathrm{dB}$ SPL, and then decreased in $5 \mathrm{~dB}$ steps as the level of the continuous tone was decreased from 90 to $50 \mathrm{~dB}$ SPL.

The frequency selected for the biasing tone was one that was within the frequency response range of the aid's microphone, but above that of the aid's receiver. 


\section{CHAPTER IV}

\section{RESULTS}

Imput/output functions shown in Figure 1 illustrate the effect of compression activation on the outputs of all four hearing aids, using a continuous $3 \mathrm{kHz}$ tone as imput. In each panel, output in dB SPL of one aid is plotted as a function of input SPL. For the Widex G6H (Figure la) minimum or maximum compresssion settings produce identical output Levels for input up to $70 \mathrm{~dB}$ SPL. Below $70 \mathrm{~dB}$, each $5 \mathrm{~dB}$ increase in input resulted in a $5 \mathrm{~dB}$ increase in output. Above $75 \mathrm{~dB}$ imput, the curve for the compression minimum condition becomes nonlinear in relation to imput, reaching a maximum output of $116 \mathrm{~dB}$ SPL. Above $70 \mathrm{~dB}$ SPL input level, the maximum campression setting also produces a nonlinear imput/output relationship, though output levels can be seen to be reduced by up to $7 \mathrm{~dB}$ more than for the minimum setting condition, indicating that compression is activated at imput levels above $70 \mathrm{~dB}$ for this aid. Figure lc illustrates a similar pattern of compression activation for the Oticon E28P. Output levels are the same regardless of compression setting for inputs up to $70 \mathrm{~dB}$ SPL, while above this point output levels are up to $8 \mathrm{~dB}$ lower when the compression is set to maximum.

The Bosch Star 66F and the Starkey SMIIPPE (shown in Figures $1 \mathrm{~b}$ and d, respectively) both show a lower threshold for compression activation than the first two aids, with output reduction apparent at inputs above 

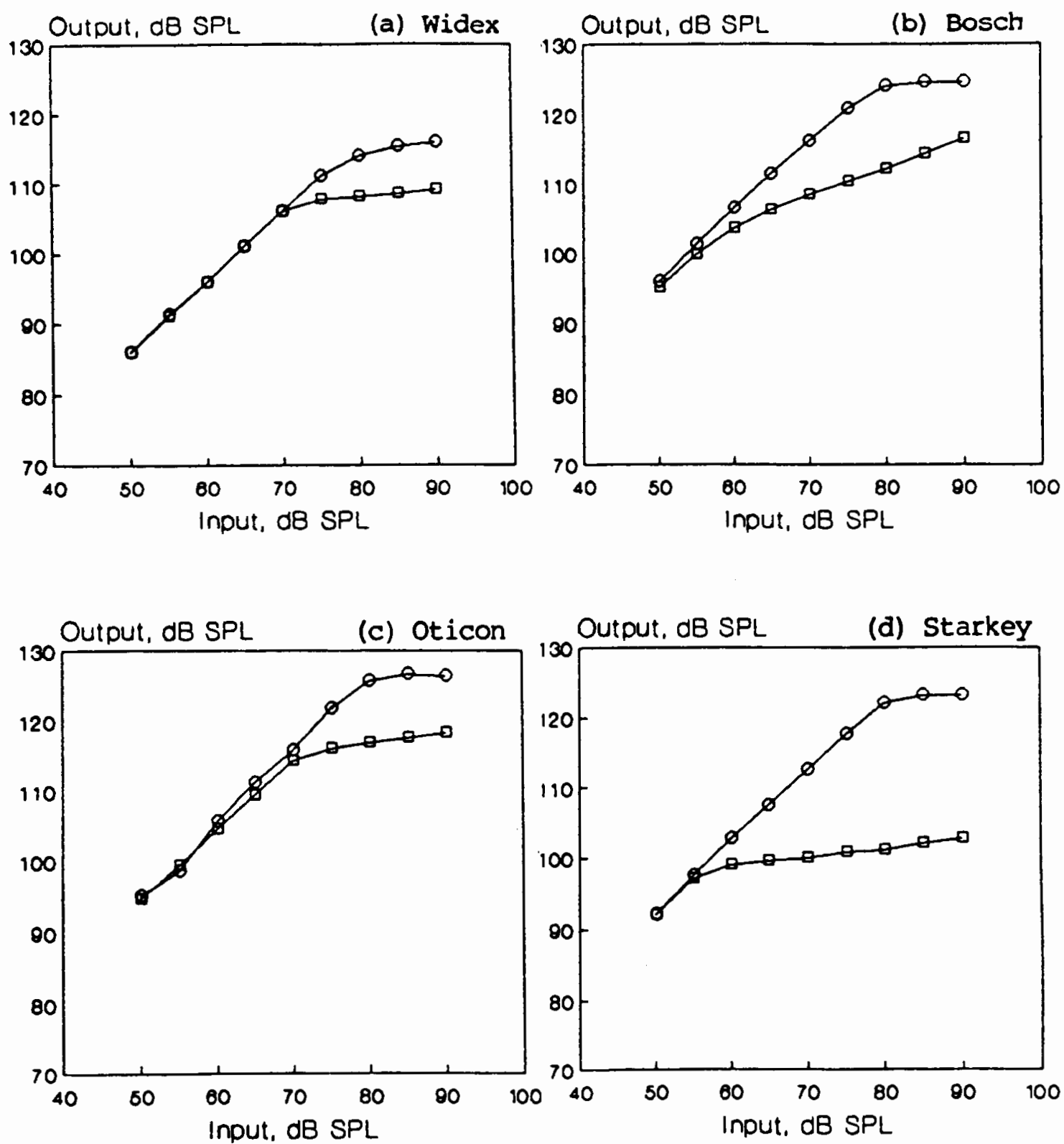

Figure 1. Input/output functions for all four hearing aids using a continuous $3 \mathrm{kHz}$ tone as input, illustrating the effects of maximum (squares) vs. minimum compression setting (circles). 
$55 \mathrm{~dB}$ SPL for each aid. Output levels are up to 3 to $12 \mathrm{~dB}$ lower with compression set to maximum than for the compression minimum condition for the Bosch, and 4 to $21 \mathrm{~dB}$ lower for the Starkey. Figure 1 thus demonstrates that the presentation of a $3 \mathrm{kHz}$ continuous tone does succeed in reducing the output levels of all hearing aids tested, when compression is set to maximum.

Figure 2 illustrates imput/output functions obtained for presentation of a transient signal with aid compression set to minimum or maximum. Output in $d B$ P.E.L. is plotted as a function of imput in $d B$ P.E.L. for each aid. For the Widex and Bosch aids (Figures $2 a$ and $b$ ), there is essentially no difference in output between the two conditions, indicating that the compression was not activated by the transient signal.

Compression setting does affect the transduction of a 1 cycle transient signal for the Oticon E28P and the Starkey SMIIPPE, as shown in Figures $2 \mathrm{c}$ and $\mathrm{d}$, respectively. For the Oticon, output levels can be seen to be nearly identical for the these conditions up to $80 \mathrm{~dB}$ P.E.L. input level. A reduction of up to $6 \mathrm{~dB}$ occurs for input levels above 80 dB P.E.L. However, switching the compression setting from minimum to maximum results in up to $6 \mathrm{~dB}$ less output reduction for the transient signal than for the continuous $3 \mathrm{kHz}$ tone (Figure 1c). For the Starkey, sutput reduction occurs at input levels above $70 \mathrm{~dB}$ P.E.L. for the maximum compression setting. As for the Oticon, the amount of reduction for the transient is less than for the continuous tone (Figure ld).

These results indicate that compression is not activated for presentation of the transient signal alone in the widex and Bosch aids. 

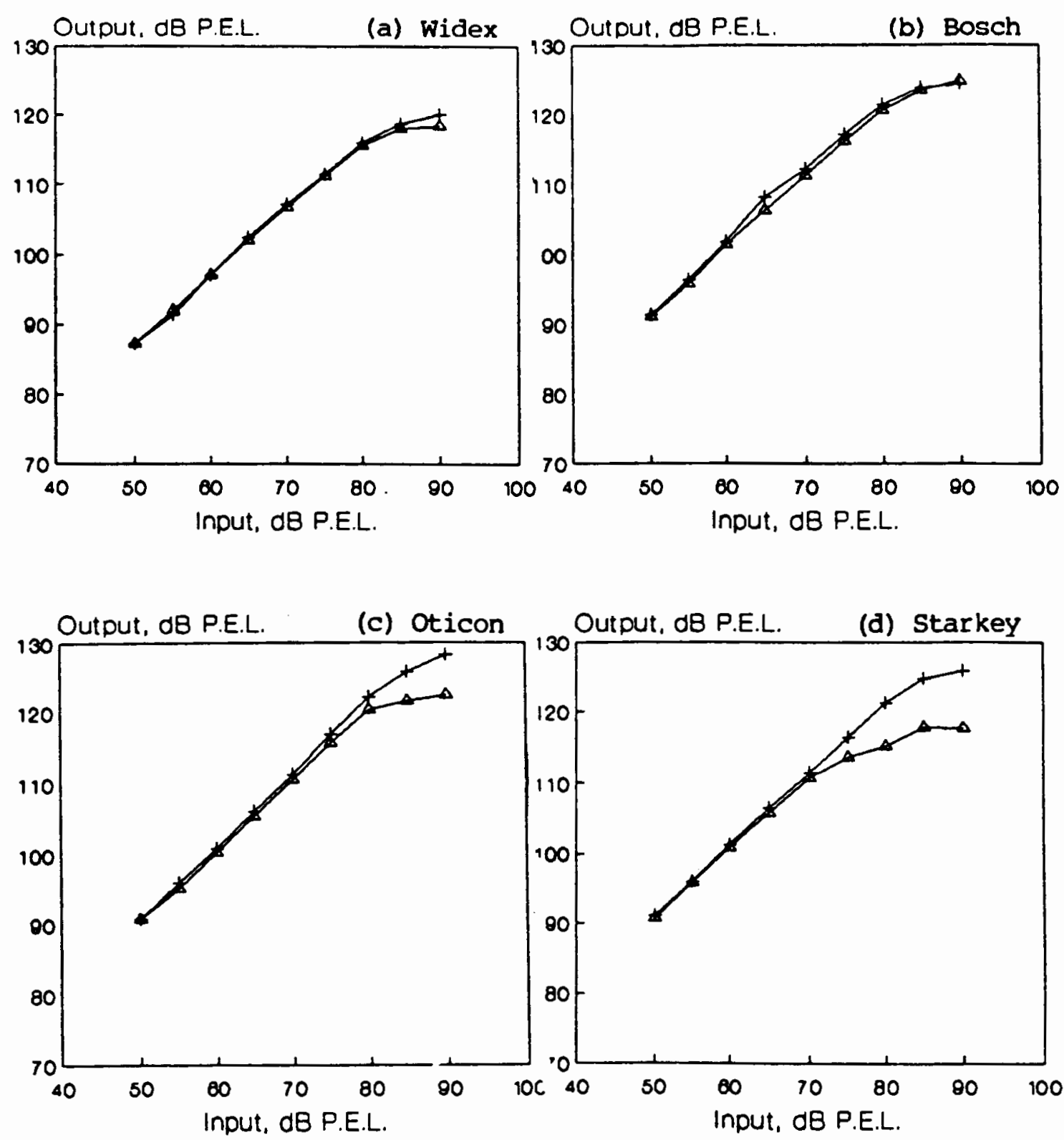

Figure 2. Input/output functions for all four hearing aids, illustrating the effects of maximum $(\Delta)$ and minimum $(t)$ compression setting on the aid's transduction of a $3 \mathrm{kHz}$ transient signal. 
Output reduction does occur for the Oticon and Starkey aids, but it begins at a higher input level and is not as great as for a $3 \mathrm{kHz}$ continuous tone.

The question of whether a biasing tone can reduce aid output for a transient signal is addressed in Figure 3, which shows power spectra (i.e., plots of output in $\mathrm{AB}$ SPL as a function of frequency) at the output of the Starkey SMII PPE. The spectrum in Figure 3a was obtained with a $90 \mathrm{~dB}$ P.E.L. transient signal alone as input with the aid's compression set to maximum. As the signal is transduced by the aid, the greatest energy concentration (shown in $\mathrm{dB} S \mathrm{SPL}$ ) can be seen around 3 $\mathrm{kHz}$, which is the frequency of the imput signal. The output level at 3 $\mathrm{kHz}$ is $96 \mathrm{~dB}$ SPL. The output above $5 \mathrm{kHz}$ is below the $55 \mathrm{~dB}$ noise rloor. Figure $3 \mathrm{~b}$ shows the effect of presenting the $90 \mathrm{~dB}$ P.E.L transient in cambination with a $10 \mathrm{kHz}$ biasing tone at $105.2 \mathrm{~dB}$ SPL. Adding the biasing tone can be seen to reduce all frequency components of the transient by approximately $11 \mathrm{~dB}$. Thus, the biasing tone does appear to activate the compression system. The level of the biasing tone at the aid's output is $57 \mathrm{~dB}$, indicating that the hearing aid is actually attenuating the high frequency biasing tone by over $48 \mathrm{~dB}$. Similar results were noted for the other 3 aids used in this study, and are shown in appendix $A$. The least attenuation of the biasing tone was seen for the Oticon E28P, where its level at output was $90 \mathrm{~dB}$.

The data thus show that the biasing tone can reduce the output level of the transient stimulus. The next step is to determine whether it can be used to modify imput/output functions for the transient such that they approximate that of a continuous signal. Figure 4 shows 


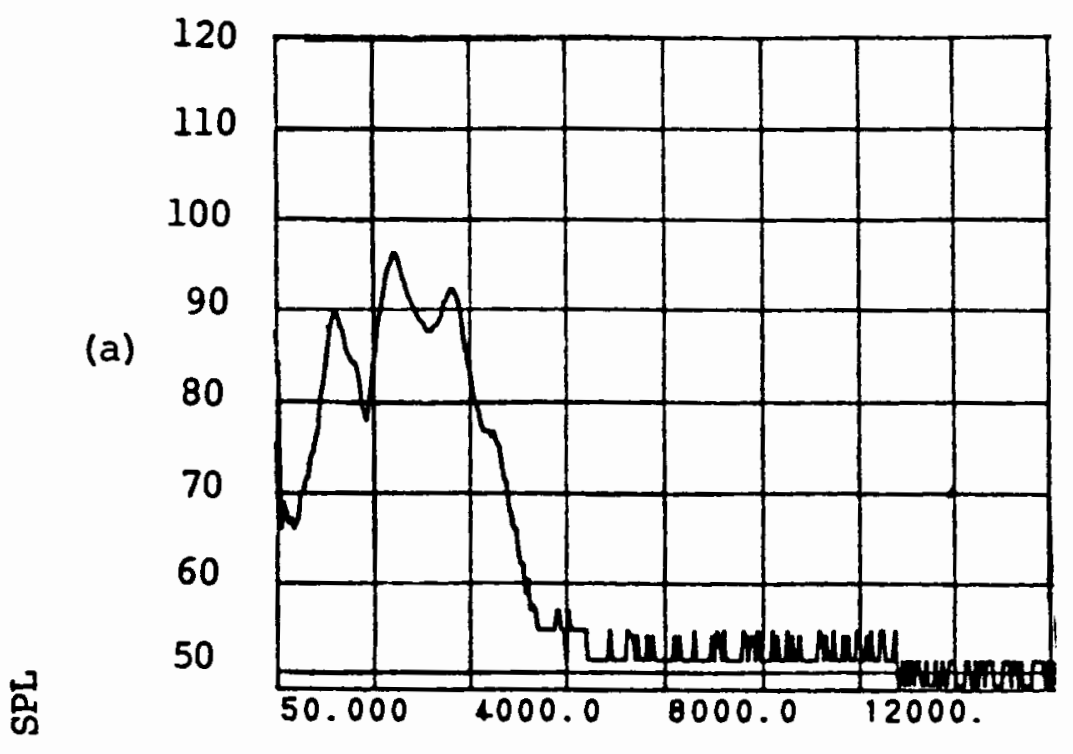

号

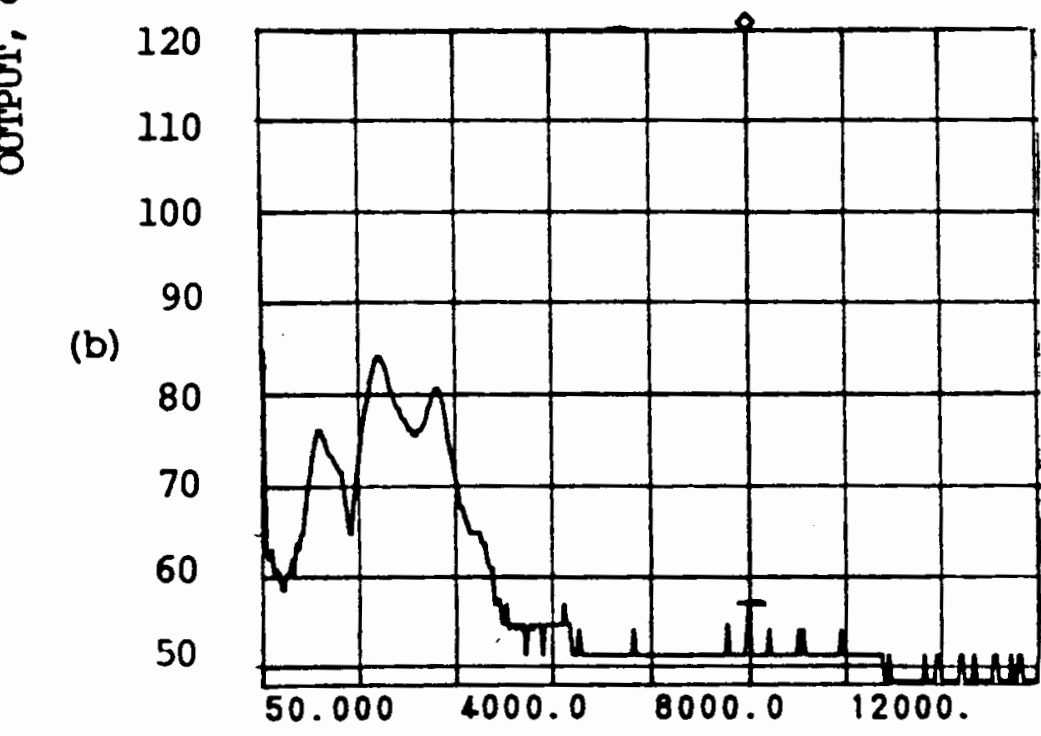

FREQUENCY, HZ

Figure 3. 'Output spectra for the Starkey SMIIPPE hearing aid with maximum compression setting, illustrating the output levels for the frequency components present as the aid transduces a $3 \mathrm{kHz}$ transient signal presented alone at $90 \mathrm{~dB}$ P.E.L. (a), as well as the aid's transduction of the same imput signal presented in combination with a $105.2 \mathrm{~dB}$ SPL $10 \mathrm{kHz}$ biasing tone (b). 

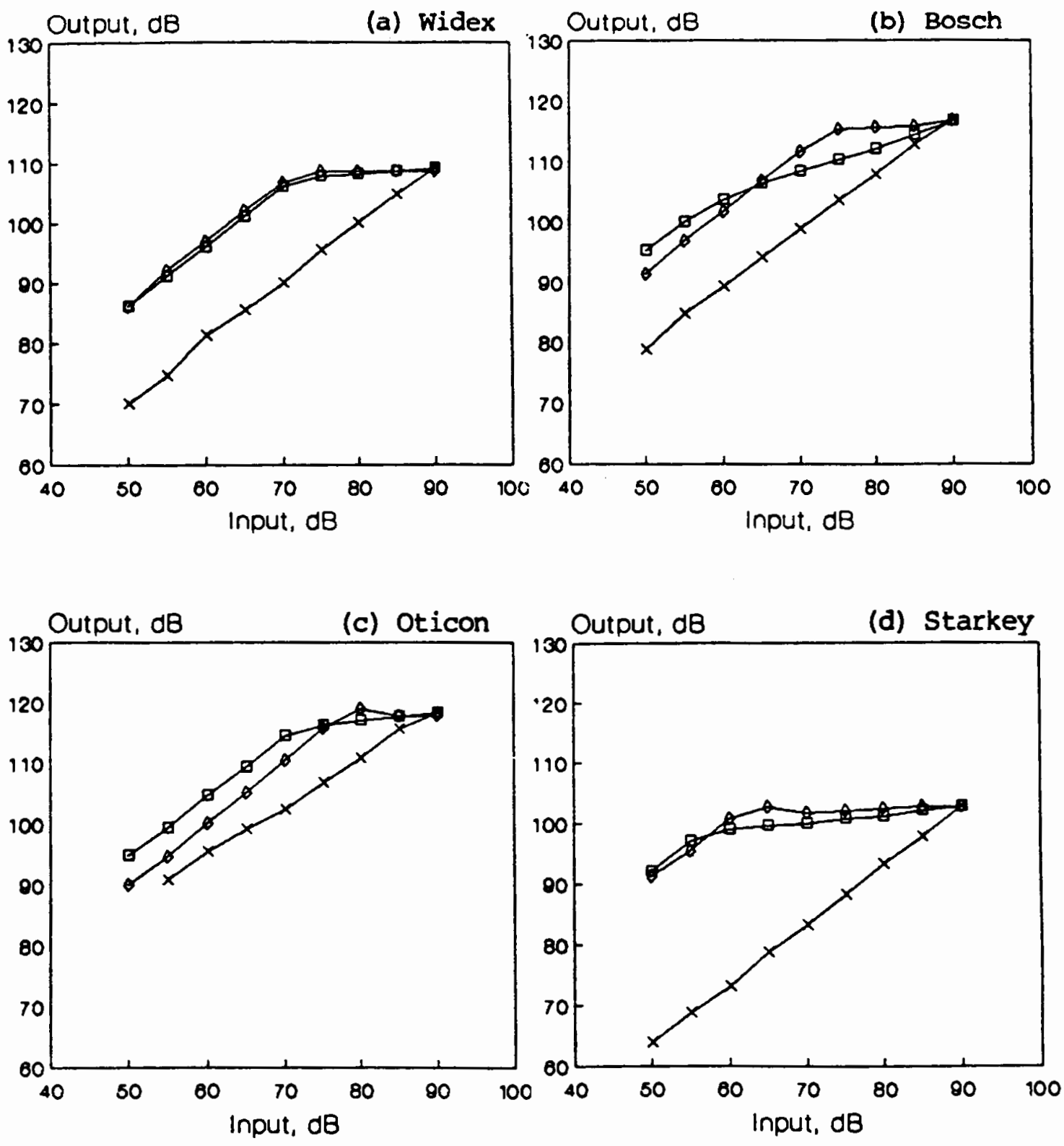

Figure 4. Input/output functions for all four hearing aids using a transient $3 \mathrm{kHz}$ input signal presented in combination with a biasing tone that is presented at a constant level $(x)$ or varied in intensity $(0)$. Also shown are input/output functions for presentation of a continuous $3 \mathrm{kHz}$ tone with aid compression set to maximum (from Figure 1 , shown here in squares). $d B$ values shown are in Peak Equivalent Level (P.E.L.) for transient signal, and in Sound Pressure Level (SPL) for the continuous $3 \mathrm{kHz}$ tone and biasing tone. 
input/output curves for all the hearing aids obtained with compression set to maximum, using as input a transient signal presented in combination with an 8 or $10 \mathrm{kHz}$ biasing tone that is either varied in intensity in $5 \mathrm{~dB}$ steps or held at a constant level. Also shown are input/output functions obtained from the $3 \mathrm{kHz}$ continuous tone presented alone for each aid (from Figure 1). Figure 4a illustrates input/output functions for these conditions for the widex $\mathrm{G} 6 \mathrm{H}$, using a $10 \mathrm{kHz}$ biasing tone at $90 \mathrm{~dB}$ SPL. Presentation of the biasing tone at a constant level produces an approximately linear relationship between input and output for the transient. Also, output levels are up to $16 \mathrm{~dB}$ below those obtained for the $3 \mathrm{kHz}$ continuous tone presentation. Figure $4 \mathrm{~d}$ shows the same test conditions for the Starkey SMIIPFE. Presentation of the 1 cycle transient with a constant level biasing tone can be seen to produce output levels that are up to $28 \mathrm{~dB}$ lower than those obtained with the $3 \mathrm{kHz}$ continuous tone. As for the Widex, linearization of the input/output function is also apparent for this condition.

The effect of a biasing tone on the transduction of the transient ミignal for the Bosch Star $66 \mathrm{~F}$ and the Oticon E28P are seen in Figures $4 \mathrm{~b}$ and $c$, respectively. These aids also show more output reduction for the transient/constant level biasing tone combination than for the $3 \mathrm{kHz}$ continuous tone presentation. In the former condition, output levels are reduced by up to $16 \mathrm{~dB}$ for the Bosch and up to $12 \mathrm{~dB}$ for the Oticon. Linear input/output functions are again apparent for this condition. Figure $4 a$ also illustrates that when the level of the transient is varied in $5 \mathrm{~dB}$ steps with the biasing tone, output levels of the Widex G6H are within $1 \mathrm{~dB}$ of those obtained for the $3 \mathrm{kHz}$ tone presentation. 
Thus, with the addition of a variable level biasing tone, the input/output function for the continuous tone can be approximated for this aid. For the Starkey (Figure 4d), output levels for the transient are within $3 \mathrm{~dB}$ of those obtained for the continuous $3 \mathrm{kHz}$ tone when the level of the biasing tone is varied. Output was also reduced for the Bosch and Oticon aids (Figure $4 b$ and $c$, respectively), but the input/output function remained different, with output up to $5 \mathrm{~dB}$ higher or lower than that obtained fram a continuous tone presentation.

Thus, it can be seen that the addition of a variable level biasing tone to the presentation of a transient signal can activate the compression to produce output of an appropriate level in two of the four nearing aids examined. However, the simultaneous presentation of a constant level biasing tone produced too much output reduction, and caused the aid's output to become Iinear in relation to input.

Finally, the effect of a high frequency biasing tone on each hearing aid's transduction of a continuous tone was examined. Figure 5 shows output levels obtained for all four hearing aids using a continuous $3 \mathrm{kHz}$ tone presented simultaneously with a constant or variable level high frequency biasing tone. Also shown are curves obtained with a $3 \mathrm{kHz}$ tone presented alone (previously shown in Figure 1). Input/output functions for these conditions for the Bosch Star 66F are shown in Figure 5b, using a $10 \mathrm{kHz}$ biasing tone. Output levels are up to $11 \mathrm{~dB}$ lower with simultaneous presentation of the $3 \mathrm{kHz}$ tone and the constant level biasing tone, and the input/output function becomes more linear, as it did for the transient signal (Figure 4). For the Oticon E28P (shown in Figure 5c) the presence of a constant level biasing tone again 

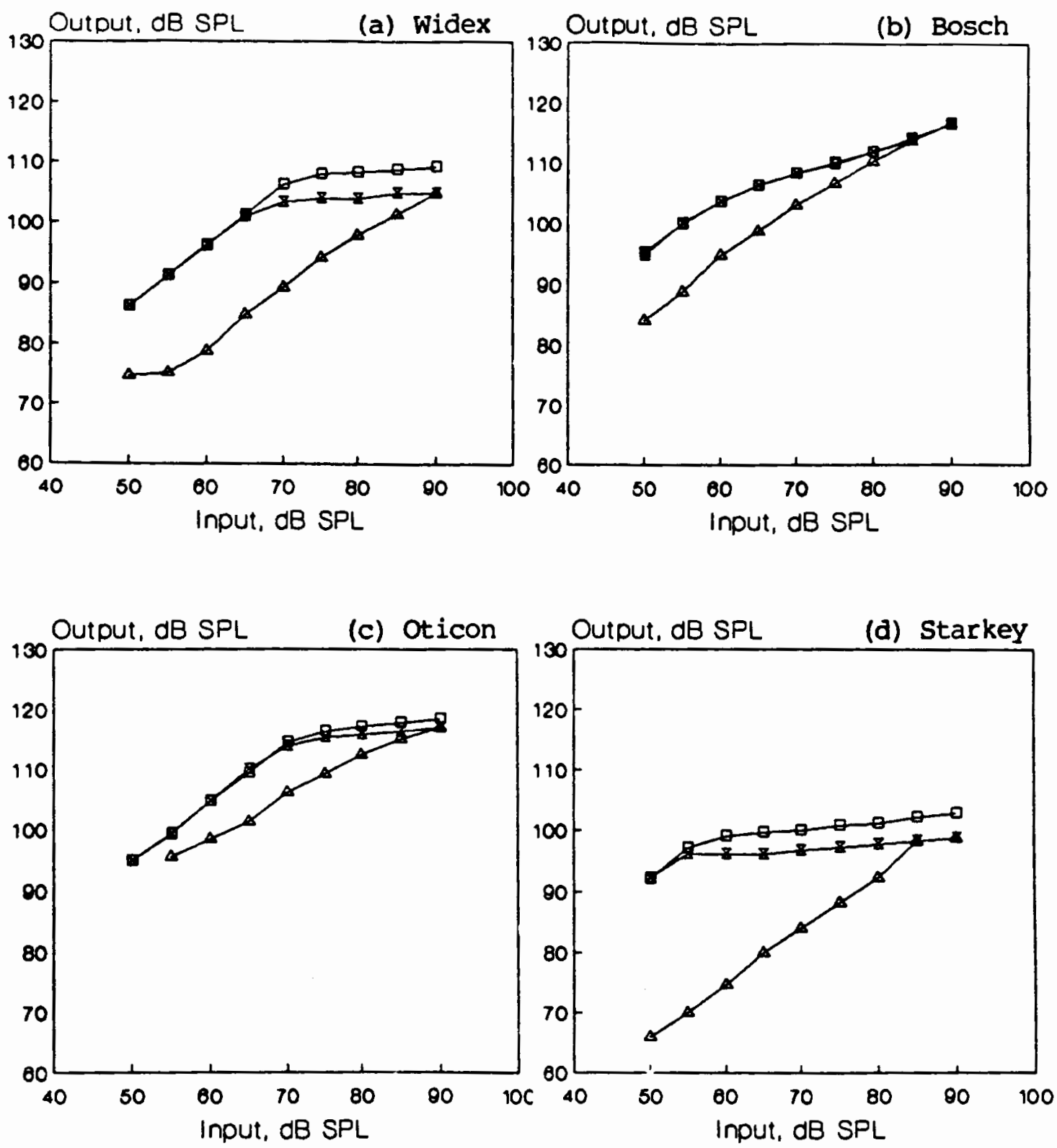

Figure 5. Input/output functions for all four hearing aids, using a continuous $3 \mathrm{kHz}$ tone as input presented in combination with a constant level $(\Delta)$ or variable level $(x)$ biasing tone, with aid compression set to maximum. Also shown are curves from Figure 1, illustrating input/output relationships for presentation of a continuous $3 \mathrm{kHz}$ tone with aid compression set to maximum (squares). 
has the effect of output linearization.

Figures $5 \mathrm{a}$ and $\mathrm{d}$ show the input/output relationships for the $3 \mathrm{kHz}$ tone with variable or constant level biasing tones for the Widex G6H and the Starkey SMIIPPE, respectively. Output levels are up to $17 \mathrm{~dB}$ lower in the presence of a constant level biasing tone for the Widex aid, and up to $27 \mathrm{~dB}$ lower for the Starkey. Again, an approximately linear imput/output function is apparent for both aids.

Figure $5 \mathrm{~b}$ also shows that for the Bosch, the $3 \mathrm{kHz}$ tone presented with a variable level biasing tone has no effect on the imput/output function, with the curve overlapping that obtained in Figure 1 for this aid. The Oticon (shown in Figure 5c) also shows little change in output levels for simultaneous presentation of the variable level biasing tone, with output levels being within $1.5 \mathrm{~dB}$ of those obtained for the $3 \mathrm{kHz}$ tone alone presentation. For the Widex G6H and the Starkey SMIIPPE (shown in Figures $5 \mathrm{a}$ and $d$, respectively), the presence of a $10 \mathrm{kHz}$ variable level biasing tone does reduce output relative to the $3 \mathrm{kHz}$ tone alone condition. Adding the biasing tone causes an additional reduction of up to $4 \mathrm{~dB}$ for both of these aids.

Thus, the addition of a constant level biasing tone tends to render the input/output function for each campression hearing aid more linear, while the presence of a variable level biasing tone has only a slight effect on the output obtained for a continuous $3 \mathrm{kHz}$ tone. 


\section{CHAPTER V}

\section{DISOUSSION}

The purpose of this study was to examine the effects of a high frequency biasing tone on a campresson hearing aid's transduction of a transient stimulus. Specifically, the intent was to determine whether the compression circuit of the hearing aid could be activated by a high frequency biasing tone such that its output for a transient stimulus could be made to approximate that of a continuous tone alone. Sufficient compression activation by a transient stimulus would mean that this type of hearing aid could be used in obtaining aided ABR measurements, since transient stimuli are commonly used for this procedure. Four hearing aids were used, and transient or continuous stimuli were introduced either alone or in combination with an 8 or 10 $\mathrm{kHz}$ biasing tone. The biasing tone was either held at one constant level or varied in intensity along with the transient or continuous signal.

The results indicate that for presentation of a transient signal alone, output reduction occurred for only two of the hearing aids, but not to the same degree as for the continuous $3 \mathrm{kHz}$ tone presented alone. when a biasing tone was added and varied in intensity with the stimulus, successful compression activation was noted for two of the aids, while the remaining two aids showed output levels that were either higher or lower than the target values. Overall, these results agree with those 
of Berg (1989) who suggested that output reduction for transient stimuli can be made to occur for some, but not all, hearing aids.

Compression activation for a transient signal is desirable if one is attempting to use $\mathrm{ABR}$ in the selection of a hearing aid for a nonresponsive client, since brief duration stimuli are cammonly used for this procedure. A compression hearing aid might be used in this situation to avoid exceeding the client's level of discomfort. If compression activation is occurring in the desired manner, the results of aided $A B R$ testing can be regarded as a reasonably accurate representation of how the client's hearing is affected by the addition of an aid.

The results of this study indicate that compression activation can be made to occur for presentation of a transient stimulus, but since each hearing aid exhibits different frequency response characteristics, compression thresholds, and attack and release times, the success of this procedure will depend upon which hearing aid is used. This would necessitate testing each hearing aid in the manner described prior to its use in ABR testing, to determine if the procedure is successful for that particular aid. If not evaluated beforehand, hearing aid output may be higher or lower than believed, leading to inaccurate ABR interpretation. Unfortunately, such prior testing would be time consuming and would require a great deal of additional instrumentation. As such it may not be practical for clinical use.

An interesting finding of this study concerned output levels in the presence of a constant level biasing tone. Specifically, the addition of a high intensity, constant level biasing tone consistently created a 
fixed amount of gain reduction, resulting in a linearization of the input/output function. This was noted for all the hearing aids, regardless of whether the primary signal was transient or steady state. This linearization of output would seem to defeat the purpose of compression, which is to amplify sounds in a nonlinear fashion such that with higher intensity input the output can be compressed to levels within the user's dynamic range. Dynamic range is defined as the range of intensities between the individual's threshold of detection and threshold of loudness discomfort.

This output reduction raises the question of how compression hearing aids function in the presence of high intensity background sounds in everyday situations. If output characteristics become altered in such conditions, it could result in user dissatisfaction, and could be a contributing factor to the relative lack of success of fittings for this type of aid. Certainly high frequency pure tones such as used in this study are not present in day to day situations, but perhaps the use of different types of background stimuli, such as broad band noise, could be used to further evaluate the output characteristics of compression hearing aids.

In conclusion, the use of biasing tones can be successful in reducing the output of compression hearing aids, though the procedure is probably not viable as an adjunct to ABR. It is hoped that fur ther research in this area will more clearly define output characteristics of compression hearing aids, which will lead to improvements in design and function that will hopefully result in greater user satisfaction. 


\section{REFERENCES}

American National Standards Institute/Acoustical Society of America (1982). American National Standards Specifications of Hearing Aid Characteristics, ANSI S3.22-1982. New York: ANSI.

Beauchaine, K.A., Gorga, M.P., Reiland, J.K. , \& Larson, L.L. (1986). Applications of ABR's to the hearing aid selection process: Preliminary data. Journal of Speech and Hearing Research, 29, 120-128.

Beauchaine, K.A., \& Gorga, M.P. (1988). Applications of the auditory brainstem response to pediatric hearing aid selection. Seminars in Hearing, 9, 61-74.

Berg, M.A. (1989). The output of compression hearing aids with a transient imput signal. Master's thesis. Portland, Oregon: Portland State University.

Cox, C., \& Metz, D. (1980). ABER in the prescription of hearing aids. Hearing Instruments, 31, 12-15, 55.

Glattke, T.J. (1983) . Short Latency Auditory Evoked Potentials. Austin: Pro-ed.

Sorga, M.P., Beauchaine, K.A., \& Reiland, J.K. (1987). Comparison of onset and steady-state response of hearing aids: Implications for use of the auditory brainstem response in the selection of hearing aids. Journal of Speech and Hearing Research, 30, 130-136.

Hall, J.W., \& Ruth, R.A. (1985). Acoustic reflexes and auditory evoked responses in hearing aid evaluations. Seminars in Hearing, 6 , 251-277.

Hecox, K.E. (1983). Role of auditory brainstem responses in the selection of hearing aids. Ear and Hearing, 4, 51-55.

Kiessling, J. (1982) Hearing aid selection by brainstem audiometry. Scandinavian Audiology, 11, 269-275.

Kileny, P.P. (1982). Auditory brainstem responses as indicators of hearing aid performance. Annals of Otology, Rhinology, $\underline{\text { O }}$ Laryngology, 91, 61-64. 
Mahoney, T.M. (1985). Auditory brainstem response: Hearing aid applications. In J.T. Jacobson (Ed)., The Auditory Brainstem Response. (pp. 349-370). San Diego: College-Hill Press.

MCPherson, D.L., \& Clark, N.E. (1983). ABR in hearing aid utilization: Simulated deafness. Hearing Instruments, 34, 12-15, 66.

Mjoen, S. (1981). ABR in pediatric audiology. Scandinavian Audiology, 13 (Suppl.), 141-146.

Preves, D.A., Beck, L.B., Burnett, E.D., \& Teder, H. (1989). Input stimuli for obtaining frequency responses of automatic gain control hearing aids. Journal of Speech and Hearing Research, 32, 189-194.

Sanders, J.W. (1983). The slow brainstem response in pure tone audiometry and hearing aid evaluation. Hearing Instruments, 34, $16-20$.

Schwartz, D.M. \& Berry, G.A. (1985). Normative aspects of the ABR. In J. Jacobson (Ed) ., The Auditory Brainstem Response (pp. 65-98). San Diego: College-Hill Press.

Weber, B.H., Seitz, M.R., \& McCutcheon, M.J. (1981). Quantifying click stimuli in auditory brainstem response audiometry. Ear and Hearing, 2, 15-19. 
APPENDIX

OUTPUT SPECTRA

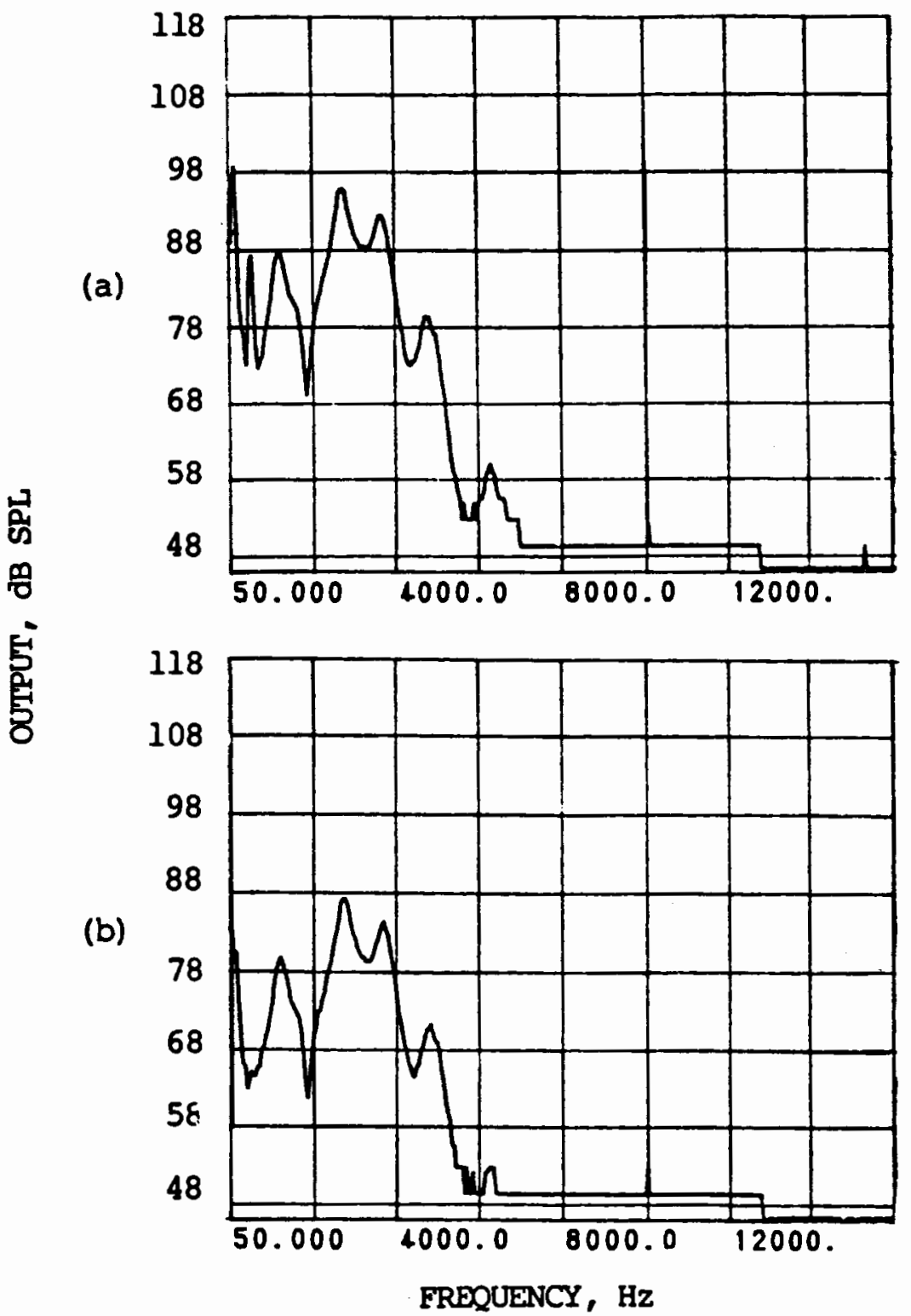

output spectra for the widex G6H, showing output in dB SPL as a function of frequency. Imput stimulus was a $3 \mathrm{kHz}$ transient signal presented alone at $80 \mathrm{~dB}$ P.E.L. (a), and with simultaneous presentation of a $10 \mathrm{kHz}$ biasing tone presented at $90 \mathrm{~dB}$ SPL (b), with compression set to maximum for both conditions. 


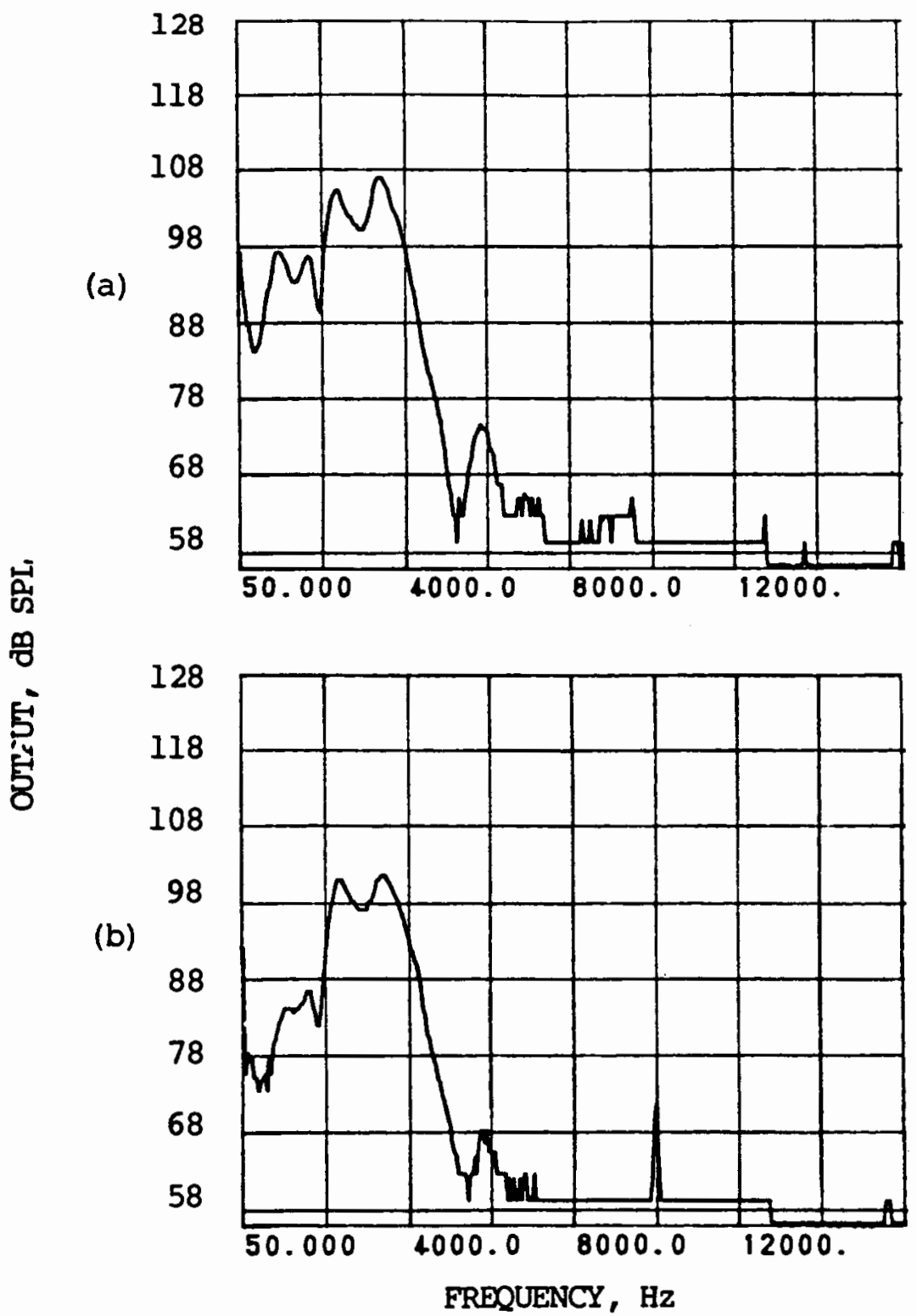

Output spectra for the Bosch Star 66F AGCI, showing output in $d B$ SPL as a function of frequency. Input stimulus was a $3 \mathrm{kHz}$ transient signal presented alone at 90 dB P.E.L. (a), and with simultaneous presentation of a $10 \mathrm{kHz}$ biasing tone presented at $86.5 \mathrm{~dB}$ SPL (b). Aid compression was set to maximum for both conditions. 


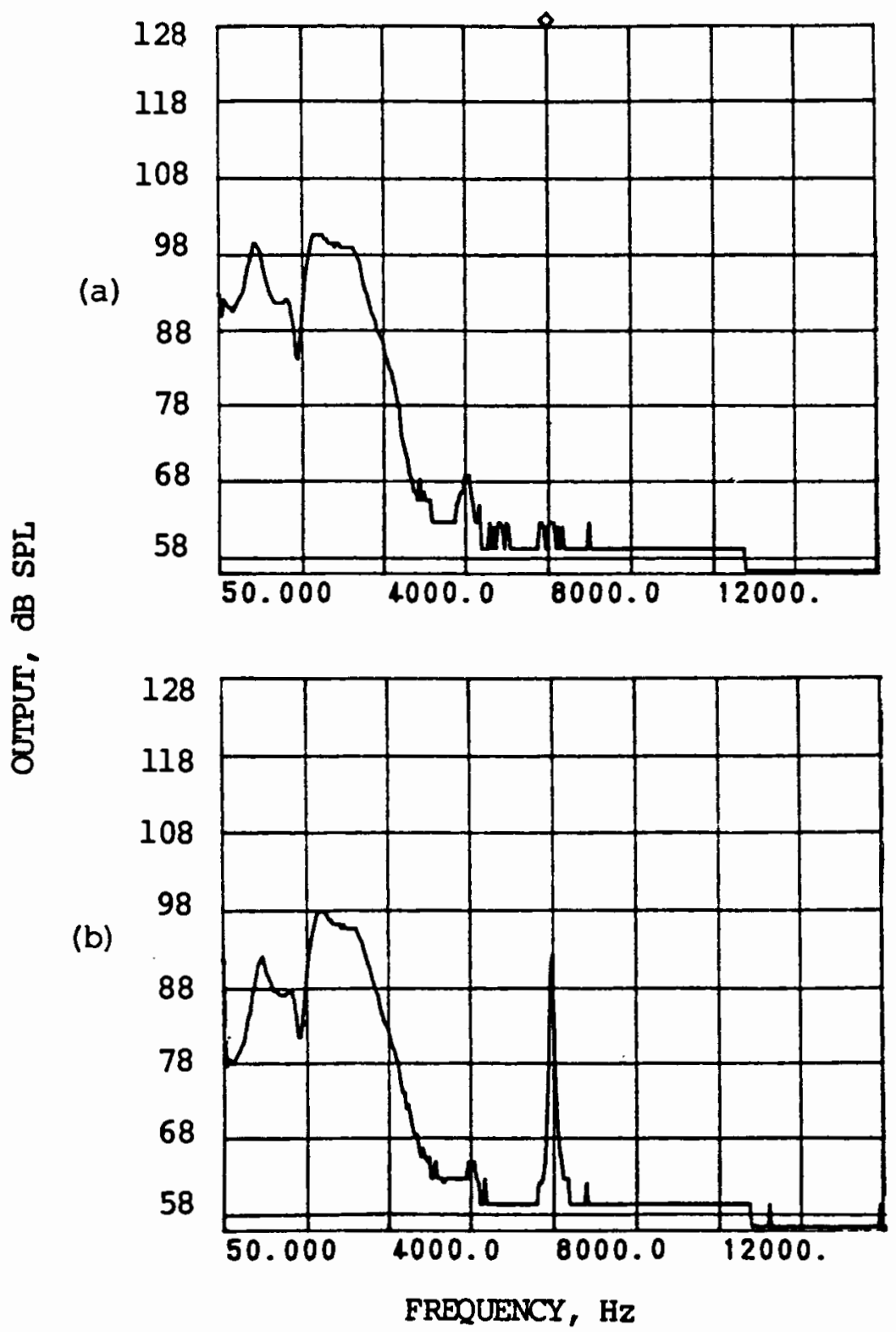

Output spectra for the Oticon E28P, showing output in dB SPL as a function of frequency. Input stimulus was a $3 \mathrm{kHz}$ transient signal presented alone at $90 \mathrm{~dB}$ P.E.L. (a), and with simultaneous presentation of an $8 \mathrm{kHz}$ biasing tone presented at 95.1 dB SPL (b). Aid compression was set to maximum for both conditions. 